\title{
CARTOGRAFİA Y HORIZONTES DE LA SOCIOLOGÍA SOBRE AMÉRICA LATINA
}

\section{Mapping and horizons of sociology about Latin America}

\author{
Danilo Martuccelli* \\ * Université Paris Descartes, USPC, miembro del IUF, Cerlis-CNRS (Francia) \\ danilomartuccelli@gmail.com
}

Palabras clave

América Latina

Lengua

Posiciones

intelectuales

Lugares

Itinerarios

\section{Keywords}

Latin America

Language

Intelectual

positions

Places

Itineraries

\section{Resumen}

El artículo propone, desde una trayectoria profesional específica, una reflexión acerca de la sociología sobre América Latina. Luego de un rápido esbozo de un conjunto de grandes perfiles de investigadores sociales trabajando sobre la región, el texto se centra alrededor de tres grandes temas. En primer lugar, la cuestión del uso y de la elección de la lengua de trabajo (y tras ello, la cuestión central del destinatario de la sociología). Luego se abordan algunas de las diferencias existentes entre mundos intelectuales construidos en torno ya sea a posiciones profesionales dentro de campos bien delimitados, ya sea a lugares más inconsistentes que se construye sobre la base de itinerarios más o menos personales. Por último, el artículo propone un análisis sobre los posibles avatares de la noción misma de "América Latina" en un momento de transformación de las condiciones de producción de la sociología sobre ella.

\section{Abstract}

This paper proposes, from a specific professional trajectory, a reflection on the sociology of Latin America. After a quick sketch of a large set of social profiles of researchers working on the region, it focuses on three major issues. Firstly, the use and choice of the language in which one works (and behind this question the central issue of the recipient of sociology). Secondly, the differences between intellectual worlds that are built either upon professional positions with well-defined areas or more inconsistent places built upon more or less personal itineraries. Finally, the paper presents an analysis about the possible destinies of the notion of "Latin America" within a time of transformation of sociological production.

Martuccelli, D., 2015, "Cartografía y horizontes de la sociología sobre América Latina", en Papeles del CEIC, vol. 2015/1, no 114, CEIC (Centro de Estudios sobre la Identidad Colectiva), Universidad del País Vasco, http://dx.doi.org/10.1387/pceic.13012 


\section{INTRODUCCIÓN}

Existen dos grandes maneras de practicar un ejercicio reflexivo sobre la producción intelectual y sobre el propio itinerario profesional. En primer lugar, el trabajo de reflexividad sobre el propio trabajo científico toma la forma de una introspección biográfica, en donde, desde el origen familiar o desde algunas grandes experiencias vividas (sociales, culturales o políticas), se intenta descifrar las orientaciones intelectuales de un trabajo'. En segundo lugar, y a veces en complemento con el procedimiento precedente, es desde las posiciones sociales particulares que se ocupan, ya sea de clase, ya sea dentro de un campo intelectual, como se trata de explicitar las coordenadas de un trabajo intelectual.

En lo que sigue, y cruzando por momentos libremente estas perspectivas, intentaré proponer al lector una travesía distinta. Sin menoscabo de lo que la presentación que propondré debe a mi propio itinerario y contexto de producción, lo que me interesará sobre todo será diseñar una cartografía personal de un conjunto de perfiles que me parecen particularmente significativos para comprender, en el momento actual, las bases de la producción sociológica sobre América Latina.

Antes de presentar una cartografía de estos perfiles, y detallar la dirección central de este artículo, dos aclaraciones previas se imponen. En primer lugar en este texto hablaré de la sociología sobre América Latina para hacer referencia de manera conjunta a lo que a veces se diferencia como la sociología latinoamericana (aquella que es producida, esencialmente por oriundos de países de América Latina, en América Latina) y la sociología latinoamericanista (aquella producida, en el Norte, por especialistas por lo general oriundos de estos países). La dicotomía, sin dejar de ser válida en muchos aspectos, impide cada vez más sin embargo dar cuenta, como lo veremos, de la pluralidad actual de situaciones y perfiles ${ }^{2}$. En segundo lugar, y con el fin de plegarme a la propuesta de este número de Papeles del CEIC, emplearé -en contra de lo que es mi costumbre- la primera persona, y haré referencias

\footnotetext{
${ }^{1}$ En Francia esta perspectiva de auto-análisis y de auto-reflexividad profesional ha sido particularmente explorada en una serie de seminarios, durante varios lustros, por Vincent de Gaulejac en el Laboratoire du changement social. Para una sintesis de estos testimonios (Bouilloud, 2007). Para mi propio testimonio, dentro de esta perspectiva, y por ende radicalmente diferente a la que desarrollaré en este artículo (Martuccelli, 2007).

${ }^{2}$ Se trata incluso de uno de los objetivos centrales de este artículo: proponer, menos una cartografía de trayectorias, a tal punto los desplazamientos y las conexiones son diversas, sino presentar, a partir de una interpretación voluntariamente esquemática de ellas, una reflexión sobre los problemas y promesas de la sociología sobre América Latina hoy.
} 
reiteradas a mis propios trabajos y trayectoria profesional. Sin embargo, no por ello desviaré de mi objetivo final: reflexionar sobre las posibles consecuencias que los contextos de producción ejercen sobre la imaginación sociológica. O sea, incluso si el artículo es una reflexión, desde un lugar profesional y un itinerario personal, trataré de dar cuenta desde ella del momento actual de la sociología sobre América Latina.

\section{NUEVOS Y VIEJOS PERFILES}

La hipótesis de partida es simple: desde hace unas décadas se afirman progresivamente nuevos perfiles de investigadores sociales en la sociología sobre América Latina. Esta emergencia indica la aparición de un nuevo momento institucional e histórico de su producción, lo que trae como posible consecuencia $-y$ es lo que más nos interesa desentrañar - un conjunto de inflexiones en las miradas analíticas.

Para caracterizar este momento de producción, partiré esbozando un conjunto - no exhaustivo- de ciertos perfiles contemporáneos -antes de extraer en los apartados siguientes-, las consecuencias de lo que esto implica para la producción sociológica. La elección de estos seis perfiles no implica, por supuesto, ningún juicio de valor, ni niega otras variantes profesionales posibles. Sin embargo, estos seis perfiles intelectuales (en términos de itinerarios profesionales y de contextos de producción) me parecen los más significativos a la hora de caracterizar el momento actual de la sociología sobre América Latina.

1) Los formados (en el exterior). En primer lugar, tras una aparente -y en verdad engañosa- profunda continuidad con el pasado, existe un grupo significativo de sociólogos que producen estudios sobre América Latina, esencialmente desde sus propios países de origen, pero luego de una estadía (por lo general estudios de maestría o de doctorado) sobre todo en Estados Unidos o en Europa, pero también en México o Brasil. Sin que esto suponga desconocer la existencia de científicos sociales que, en el pasado, no tuvieron esta formación, no es injusto afirmar que la mayor parte de las figuras más relevantes de la sociología latinoamericana tuvieron en el pasado experiencias de formación de este tipo. En verdad, se trata de una experiencia de larga tradición en América Latina, y que excede a la sola sociología, puesto que reenvía a los viajes de formación de tantos intelectuales desde el siglo XIX - por no remontar hasta la época de la Colonia-. Este ir y venir fue, y en parte es, aún tan importante que podría 
incluso hablarse de la experiencia habitual de muchos de los sociólogos en la región. Sin embargo, y es lo que me interesará subrayar, a pesar de su indudable continuidad, este perfil posee hoy rasgos diferentes, a medida que se afirma la internacionalización de la sociología, y que los escenarios nacionales de producción se vuelven más consistentes.

2) Los formados (en el pais). En segundo lugar, aparece progresivamente, con mayor fuerza sobre todo en los paises con mayor producción nacional -Brasil, México, Argentina- una generación de sociólogos nacionales que, formados exclusivamente en su propio país, ejercen en el propio país. Esta figura profundamente nacional es paradójicamente un perfil contemporáneo a la era de la globalización -en verdad, un resultado colateral en el ámbito de las ciencias sociales del crecimiento de los países emergentes-. La novedad de este perfil de sociólogos no solamente se verifica a través su incremento numérico, sino también, en verdad sobre todo, por el abanico de los lugares profesionales en los que ejercen. Ayer, se trató por lo general de trayectorias confinadas a la experiencia de sociólogos provincianos o en universidades capitalinas juzgadas periféricas; hoy, este perfil convoca un grupo heterogéneo de sociólogos que ejercen y enseñan la sociología progresivamente en todos los centros profesionales disponibles ${ }^{3}$. Digámoslo de paso: estos dos primeros perfiles son hoy por hoy mayoritarios en la producción sociológica sobre América Latina.

3) Los emigrantes. En tercer lugar, en las últimas décadas, y aquí también a la vez en continuidad e inflexión con el pasado, se consolida un grupo, sin duda numéricamente más significativo de investigadores sociales, de origen latinoamericano, que trabajan en universidades europeas o norteamericanas, produciendo estudios "desde el exterior" acerca de América Latina (en verdad, en mucho sobre sus propios países de origen), pero que también se abren progresivamente, y en esto señalan una indudable novedad, a realizar investigaciones sobre las propias sociedades del Norte -Estados Unidos o Europa- en las cual residen.

\footnotetext{
${ }^{3}$ Una aclaración. Dentro de este perfil es posible diferenciar un sub-grupo de investigadores que no solamente tiene poco contacto con el extranjero sino que incluso cuestiona, radicalmente, desde su trayectoria y contexto de producción, el interés de la apertura intelectual en nombre de un esencialismo identitario. Se dará cuenta en el análisis que sigue de la especificidad de este perfil de varias maneras.
} 
4) Los fronterizos. En cuarto lugar, se consolida también progresivamente un grupo de sociólogos latinoamericanos que residen y trabajan en un país de la región distinto al que nacieron. Si algunos ejemplos célebres de desplazamientos intrarregionales pueden evocarse en el pasado, y mucho antes del nacimiento de la sociología - pensemos al magisterio del venezolano Andrés Bello en Chile-, se trató en el fondo, y hasta hace poco, de una figura numéricamente marginal. A lo sumo, se trató de experiencias fomentadas por los exilios políticos propiamente dichos, que dieron lugar a colaboraciones importantes, e incluso decisivas, como lo ejemplifican célebres trabajos de la escuela de la dependencia en los años sesenta y setenta. Sin embargo, como perfil, se trató de experiencias puntuales, aunque mal no sea porque la inserción de estos profesionales latinoamericanos en sus países huéspedes pocas veces dejó, realmente, de vivirse como una experiencia transitoria. En el fondo, la trayectoria de Néstor García Canclini, y su tránsito de un exiliado argentino a la experiencia de uno de esos "mexicanos que nos dio el mundo" es más una brillante excepción que una regla; incluso si su camino, y su perfil, abstracción hecha de la experiencia directa del exilio, es cada vez más importante entre los sociólogos latinoamericanos 4 .

5) Los inmigrantes. En quinto lugar, en los últimos lustros, se asiste al eclipse de la presencia del Gran intelectual -o visitante- europeo (más que estadounidense) en América Latina, y su relevo por nuevas generaciones de profesionales que, nacidos y formados en Europa o en los Estados Unidos, se instalan en algún país de la región. En este perfil, y más allá de los renombres, el contraste es relevante entre la inserción intelectual lograda en el pasado por algunos sociólogos, como el italiano Gino Germani en Argentina, los españoles Medina Echevarria o Roger Bartra en México o Jesús Martin Barbero en Colombia, o la de un alemán como Norbert Lechner en Chile, y la experiencia de las nuevas generaciones que han comenzado a insertarse, y podrian continuar insertándose laboralmente en América Latina, dada las dificultades observables en los mercados de trabajo para las ciencias sociales en Europa o Estados Unidos.

\footnotetext{
${ }^{4}$ Una vez más: mi objetivo en este apartado es solamente diseñar algunos grandes perfiles. Obviamente, dentro de un mismo perfil, es posible rastrear muchas diferencias: no es lo mismo ser boliviano en México, peruana en Chile o uruguayo en Argentina.
} 
6) Los foráneos. El sexto y último perfil, como el primero, se inscribe en una engañosa continuidad. Se trata de un conjunto de especialistas europeos y estadounidenses (progresivamente asiáticos 5 ) que, desde sus países de origen, trabajan sobre América Latina. Aquí también es necesario reconocer la profundidad de la inflexión detrás de la aparente continuidad: hasta hace unas décadas se trataba casi exclusivamente de figuras individuales, especialistas reconocidos de un área geográfica y cultural pero que tenían muy poca, o ninguna incidencia o relación, con la producción mainstream de las ciencias sociales de su propio país. En este perfil, regresaremos en un momento, una verdadera escisión se observa actualmente según que se lo aborde desde los Estados Unidos, en donde un verdadero campo intelectual se ha construido en torno a los Latin American Studies; o desde Europa en donde, a pesar de importantes diferencias nacionales, sigue en el fondo tratándose por lo esencial de experiencias individuales.

En lo que sigue, apoyándome reflexivamente en el perfil en el cual se inscribe mi experiencia profesional -emigrante-, trataré de esbozar un conjunto de desafíos específicos del momento actual de la sociología sobre Latinoamérica. Me centraré en tres puntos: la problemática de la lengua y la cuestión del destinatario de la producción sociológica; la cuestión de las posiciones o de los lugares como contextos de producción; finalmente, las posibles transformaciones que esta heterogeneidad de perfiles entraña para el futuro del imaginario sociológico sobre América Latina.

\section{LENGUAS Y DESTINATARIOS}

Aplico la regla: intentaré proponer una serie de reflexiones partiendo desde el perfil en el cual me inscribo - una generación de investigadores de origen latinoamericano que fueron a estudiar en el extranjero y que se insertaron profesionalmente en estos países-. Como lo indiqué, los miembros de este grupo tienen experiencias muy disímiles según se trate de investigadores que trabajan exclusivamente sobre América Latina o que realicen estudios también sobre algún país del Norte. Regresaré sobre este aspecto -crucial- de mi propio perfil grupal en

\footnotetext{
${ }^{5}$ Investigadores que, por el momento, incluso a pesar del creciente interés por sus trabajos, tienen empero por el momento, y a diferencia de sus pares europeos o estadounidenses, una menor inserción en las redes de producción latinoamericanas.
} 
un momento, por ahora quisiera indicar algo que me parece es común y esencial a la producción intelectual actual. Para explicitarlo, tomaré como brújula la relación de los sociólogos con la lengua.

Inmediatamente aparece una diferencia mayúscula: para caracterizar el momento actual de la sociología sobre América Latina la experiencia del exilio deja de ser un factor decisivo -como lo fue en mucho en el pasado- de la producción sociológica. En efecto, la figura del exiliado es radicalmente insuficiente para describir el humus intelectual de los diversos perfiles de investigadores sociales evocados. En algunos, por supuesto, los de mayor edad, el exilio político es una experiencia directa, y en otros, una experiencia familiar, pero incluso entre estos últimos, el exilio deja de marcar, salvo tal vez en los estudios sobre los detenidosdesaparecidos o sobre la migración, el horizonte de la imaginación sociológica. En todo caso, el hilo conductor del problema de la lengua revela lo difícil que es reactivar la figura del exilio para dar cuenta de la relación que en el momento actual de producción los sociólogos trabajando sobre la América Latina tienen con las lenguas en las cuales trabajan y escriben.

\subsection{La lengua más allá de la condición política}

Para entender las especificidades en este punto de la sociología sobre América Latina, me parece indispensable comenzar por comprender, más allá de las experiencias personales, lo que puede caracterizarse como la condición política de la lengua. Si se deja de lado la relación que con la lengua española tienen las minorías lingüísticas en la región, y que no es la mía - hispanohablante de nacimiento-, la relación con la lengua castellana (o portuguesa) no ha producido reflexiones similares a lo que se observa con el inglés o con el francés por parte de intelectuales o novelistas, incluso científicos sociales, que se expresan en estas lenguas desde los países del Sur 6 . y lo que es válido para el castellano, parece serlo aún más, cuando los sociólogos escriben sus trabajos en otra lengua - en la mayoría de los casos, el inglés, el francés, el alemán,

\footnotetext{
${ }^{6}$ En este punto, la diferencia es mayúscula con las ciencias sociales africanas en donde la condición política de la relación con la lengua es muy distinta, marcada por una inmediata polarización lingüística entre anglófonos, francófonos, árabes u otras lenguas nacionales y locales. Cf. las reflexiones sobre este punto de Amselle (2008). Por contraste, el castellano no ha sido objeto (¡sino en España!) de reflexiones identitarias desde las ciencias sociales; en todo caso, no existe a su respecto el equivalente de las discusiones producidas por "minorias" en torno a la lengua inglesa o francesa (alrededor del tema, por ejemplo, de la négritude).
} 
e incluso el italiano-. Entre los emigrantes y los inmigrantes -perfiles 3 y 5-, y cualquiera que sea la dificultad personal (más o menos negada que se viva en este proceso), la extranjeridad residual que se conserva con la lengua en la que se escribe y trabaja, se interpreta más en términos de una necesaria e indispensable competencia lingüística profesional que como la expresión de un desgarro identitario. En todo caso, la ausencia de testimonios elaborados sobre este punto, entre los científicos sociales, llama la atención ${ }^{7}$.

Ahora bien, como todo el mundo sabe, los acentos son un signo de extranjeridad como puede serlo un color de la piel. Pero la experiencia de la extranjeridad es distinta en ambos casos, y si tanto una como la otra pueden ser neutralizadas, incluso eliminadas, como marcadores de extranjeridad, no por ellos desaparecen jamás del todo. En el perfil de investigadores, los emigrados, o sea desde el cual produzco estas reflexiones, pero también en los fronterizos, inmigrantes e incluso foráneos, el acento (o la variación fenotípica) ejercen como un marcador de alteridad. Para dar cuenta de la particularidad de esta situación, la experiencia del personaje de la novela de Philip Roth La mancha humana es particularmente acertada más que a una discriminación abierta, muchos de estos investigadores viven esta experiencia como la de "negros" de piel muy clara, tan clara, que por momentos terminan siendo efectivamente asimilados a los "blancos"... sin jamás terminar de serlo del todo. Salvo excepciones, en el contexto profesional de las ciencias sociales, la caracterización de esta situación a través de una denuncia abierta de discriminación no puede ser sino una actitud irresponsable de mala fe; $y$, a la vez, toda negación absoluta de la diferencia, una postura ingenua ${ }^{8}$.

Lo que me interesa subrayar en este apartado no son pues las dificultades más o menos personales en este proceso de adquisición o de expresión en otra lengua (o en una misma lengua pero con otro

\footnotetext{
${ }^{7}$ Si traigo a colación la lengua es porque la relación con ella condensa un conjunto de desafíos, políticamente significativos, como lo es la situación de los indígenas no hispanohablante, una experiencia que ha sido estudiada desde las ciencias sociales, o recreada desde la literatura (por ejemplo en la obra, narrativa y etnológica, de José María Arguedas). Sin embargo, la lengua, y la condición política de la lengua, no es objeto de reflexión, bajo esta modalidad, entre los sociólogos trabajando sobre América Latina.

${ }^{8}$ Ninguna ingenuidad en esta afirmación. En términos razonables, o sea tomando como referencia la realidad del mundo del trabajo, el ámbito académico, y por extensión, los universos laborales de las ciencias sociales son probablemente uno de los sectores menos sujetos a la discriminación (incluso si la cláusula de la nacionalidad excluye de facto a muchos extranjeros de ciertos concursos).
} 
acento), lo que es - sin duda- un objeto legítimo de reflexión, sino acentuar el hecho que no es bajo la forma de un "desgarro" identitario como, por lo general, se da cuenta de este proceso. Al contrario, lo que asombra, es el silencio colectivo al respecto.

\subsection{Lo que el empleo de una lengua produce en las ciencias sociales}

Para comprender la función de la relación con la lengua, es preciso elegir otra vía. Se dice habitualmente, como lugar común, que la verdadera nacionalidad de un escritor es su lengua. Si la afirmación es plausible para la literatura puesto que refleja, sin duda, el vínculo "visceral" que un escritor tiene con las palabras, una aseveración de este tipo es incapaz de hacer justicia a los procesos de elección de la lengua entre los investigadores sociales. En este ámbito, si las diferencias son transversales entre los diferentes perfiles, dos tipos de relaciones sobresalen.

En primer lugar, el portugués y el español siguen siendo las principales lenguas empleadas por las ciencias sociales en la región, lo que señala, sobre todo en comparación con las ciencias naturales, la fuerte articulación de estas disciplinas con las lenguas vernáculas. Esto es algo que es incluso todavía válido, aunque cada vez más marginalmente, entre algunos investigadores foráneos. En segundo lugar, estimulado por las exigencias de la evaluación y la estandarización universitaria, la producción en las ciencias sociales, más allá del lugar de trabajo en donde se ejerce, tiende a realizarse en inglés - sobre todo entre las generaciones más jóvenes y a medida que el artículo científico destrona al libro como principal vehículo de expresión en las ciencias sociales (Ortiz, 2009)-. Una dimensión y preocupación que, notémoslo, también es visible, marginalmente por el momento, entre algunos investigadores formados exclusivamente en un ámbito nacional. A estas dos variantes mayoritarias y transversales de expresión, es preciso añadirle el caso más circunscrito de algunos investigadores emigrantes (en el cual, lo recuerdo, me incluyo), pero también de ciertos foráneos: sociólogos que trabajan en una lengua alógena otra que el inglés -el francés o el alemán, y más marginalmente el italiano-.

Es desde esta pluralidad lingüistica como debe abordarse una de las especificidades actuales de las ciencias sociales sobre América Latina. Por una razón muy simple: el uso de una lengua vernácula inserta un trabajo dentro de una tradición intelectual particular. Pero también 
porque la superposición -asimétrica- de lenguas comúnmente utilizadas hace de las ciencias sociales sobre América Latina un fabuloso lugar de confluencia de orientaciones intelectuales. En efecto, a pesar de la hegemonía lingüística creciente del inglés, la producción europea, sobre todo francesa, en parte española o alemana, y más marginalmente italiana, siguen gozando de una audiencia e incluso de una influencia incontestable en la región. Lo cual no impide empero (repitámoslo, a pesar de la hegemonía lingüística creciente del inglés), que lo esencial de la producción se siga haciendo en castellano y en portugués. Constatación simple sobre la que volveré en un momento: se trata pues de un ámbito de expresión lingüística en el cual las relaciones de fuerza son menos unívocas y claras de lo que habitualmente se supone.

El resultado es ambivalente. Es posible en efecto afirmar, basándose incluso, por ejemplo, en una rápida revisión de las referencias bibliográficas movilizadas por los unos y los otros, la ausencia radical de una verdadera tradición sociológica autónoma en los países de América Latina (Suárez y Pirker, 2014). Algunos pensarán en Babel, a tal punto cada cual discute con autores distintos según su lugar de formación doctoral, la fuerza del campo intelectual nacional en el cual se trabaja, por supuesto, la lengua en la que escribe. Y al mismo tiempo, y por otro lado, detrás de esta misma cacofonía es posible advertir la presencia común de ciertas "grandes" referencias. Sin embargo, lo más importante es comprender que en la era de la globalización creciente de la producción en las ciencias sociales, la sociología sobre América Latina es una expresión concreta y casi avant la lettre de lo que este nuevo horizonte de trabajo implica a nivel de las discusiones intelectuales.

Es desde esta pluralidad como deben comprenderse las consecuencias de la lengua para la producción de las ciencias sociales sobre América Latina. Para decirlo en términos simples, la lengua que se usa define, para cada investigador, el destinatario imaginario de su propio trabajo intelectual. Detrás del uso de una lengua sobre otra, lo que se define no es una identidad personal, sino la delimitación de un grupo preferente de lectores con quienes se pretende discutir. Repitámoslo: en este proceso, si la producción en lengua inglesa se generaliza entre algunos investigadores (al menos en lo que concierne la producción de ciertos artículos), la mayor parte de ellos sigue expresándose en sus lenguas vernáculas maternas. 
En mi caso personal, mi actividad profesional está menos marcada por una división lingüística, el francés y el castellano, que por una voluntad común: la elección de una u otra lengua en mis trabajos depende en mucho del público imaginario al cual me dirijo ${ }^{9}$. El empleo, en la redacción de cada uno de mis trabajos de investigación, de la propia lengua del país en el cual la investigación fue hecha, es un intento, ampliamente consciente, a pesar de sus dosis imaginarias, de dirigirme si no a la opinión pública, por lo menos, al menos potencialmente, al público lector de esos países. Entiéndase bien: en mucho ese público ilustrado y sobre todo lector de ciencias sociales, no existe. Pero ello no me impide, en absoluto, convertirlo en el destinatario imaginario de mi producción. Y, sobre todo, y es esto lo esencial, esta elección tiene efectos importantes sobre la propia producción intelectual.

No se escribe las ciencias sociales de la misma manera según la lengua que se emplee. No por razones literarias, ni tan siquiera por la inscripción dentro de una tradición cultural específica, sino sobre todo por razones de público imaginario. Cuando redacto en francés, libros o artículos, que tratan sobre la situación en Francia, o en castellano, libros o artículos que analizan el contexto latinoamericano, tengo el sentimiento de adoptar una misma postura de enunciación: me dirijo - una vez más, incluso imaginariamente- al público lector de cada una de estas sociedades $^{10}$.

Para evitar todo malentendido: esta opción, por personal que parezca, y que se entiende desde mi trayectoria biográfica y mi familiaridad ( $y$ agonía lingüística...) tanto con el francés como con el castellano, es análoga a aquellos que, escribiendo por razones de familiaridad o destreza lingüística, en sus lenguas maternas (francés, alemán, en parte inglés), tienen la preocupación, desde y en el momento mismo de la escritura, de asegurarse traducciones en castellano o portugués. Regresaré sobre este un punto, pero lo importante no es la lengua en sí

\footnotetext{
${ }^{9}$ En mi propia experiencia personal, mi uso (y con el tiempo mal uso) del castellano, ha acentuado el recurso, totalmente involuntario, a torsiones en la lengua, a imprecisiones ortográficos y de sintaxis, a una mezcla de "particularismos" nacionales de los paises en los que he investigado, sin que viva, este manejo desprolijo del castellano, y el sesgo idiosincrático que revela, como una experiencia problemática -en la medida en que logro comunicar (todavía...) sin dificultad, en mi lengua materna-.

${ }^{10}$ En lo personal nunca he escrito una investigación sobre la sociedad francesa en castellano; y nunca he redactado una investigación sobre un país de América Latina en francés (en este caso también porque los posibles interlocutores en Francia de estos estudios son por lo general hispanohablantes).
} 
misma en la que se escribe, sino el destinatario imaginario al que se apunta. Algo que también da cuenta de la importancia del libro en las ciencias sociales que, con mayor vocación que los artículos, se dirigen imaginariamente a un público lector más amplio.

Consecuencia: en términos de producción y de imaginación sociológica, lo que debe ser objeto de reflexión es pues antes que nada el grupo de lectores a quienes uno se dirige al escoger una lengua u otra. ¿Por qué? Porque esto define, más allá de los lectores potenciales o reales, el tipo de problemas sociales que se abordan. Esto es patente, creo -y espero-, en los trabajos de investigación que he hecho, a través de los años, en colaboración con colegas latinoamericanos (formados en el exterior y fronterizos): la construcción de cada una de las problemáticas estudiadas tuvo siempre en cuenta la producción local, con la cual nunca cesé -cesamos- de discutir (Martuccelli y Svampa, 1997; Sorj y Martuccelli, 2008; Araujo y Martuccelli, 2012). Por supuesto, esto no quiere decir que las preguntas planteadas, o los autores discutidos, eran todos "nacionales", lo que sería una simple tontería. Pero sí indica el universo de polémicas, indisociablemente intelectuales y políticas, en el cual cada uno de estos estudios se insertó. y lo que vengo de decir a propósito de mis estudios sobre América Latina, vale también para mis propios trabajos de investigación sobre la sociedad francesa.

\section{3. ¿Una sociología para sociólogos?}

Puesto que el objetivo de estas reflexiones no es biográfico, en este apartado tomaré como ilustración la elección -absolutamente legítima- de aquellos que hacen una elección lingüística contraria. En verdad, me centraré, por cuestiones de espacio, en la experiencia de aquellos que deciden escribir preferentemente en inglés.

Esta elección, más allá de posibles razones biográficas, no puede ser leída independientemente de la importante transformación institucional observable en las condiciones de trabajo. A saber, la aparición de una carrera de investigador y la estandarización de los criterios de evaluación, y tras ello, la consolidación de nuevas jerarquías universitarias e intelectuales. El proceso, como se sabe, no es exclusivo a las ciencias sociales contemporáneas, y es incluso una de las grandes especificidades del management contemporáneo (Martuccelli, 2010a). En la producción científica se imponen por doquier exigencias de evaluación estandarizadas $y$, progresivamente -independientemente 
incluso del lugar de trabajo-, este proceso induce a que la producción tienda a realizarse en el idioma inglés.

Voy a lo esencial: la puesta en práctica de ciertas modalidades de evaluación de las carreras de los investigadores sociales, sobre todo aquellos que trabajan en América Latina, al someter progresivamente sus carreras a procesos de estandarización productiva dictados desde cánones internacionales, produce una modificación más o menos subrepticia de la identidad disciplinaria de la sociología. Lo importante, en acorde con lo desarrollado en el apartado anterior, no reside en el empleo per se de tal o cual lengua, sino en lo que esta utilización supone en términos de destinatario de la labor sociológica.

Lo esencial no es, en el fondo, la obligación de escribir en inglés, y ni siquiera la adopción más o menos mimética de criterios de profesionalidad y de exigencias de calidad (validadas por instituciones y revistas hegemónicas del campo intelectual de ciertos paises del Norte) sino las consecuencias que esto entraña en la imaginación sociológica. El cambio parece marginal, es en verdad sustancial. Progresivamente, muchos investigadores no se dirigen más -al menos imaginariamente - al público lector de sus propios países o de las sociedades que estudian. Son ( $y$, en el fondo, se presentan) antes que nada como investigadores que, trabajando en tal o cual país, entablan comunicaciones con otros investigadores que en dicho país (o, y de más en más, en algún país del Norte) trabajan temas similares. Las consecuencias del uso del inglés - vehículo por lo demás indispensable de la comunicación científica en el mundo de hoy-deben entenderse en este marco: el recurso cada vez más exclusivo, y no esporádico, al inglés en la producción de las ciencias sociales sella, incluso simbólicamente, el divorcio entre una parte de la producción de la sociología y los debates nacionales.

Evito toda caricatura. No hay duda de que este destinatario (los colegas, a través de los artículos) es más realista que aquel que fue activo -al menos imaginariamente- en las generaciones anteriores. Si me refiero exclusivamente en este punto a la sociología latinoamericana, ésta padeció (como antes de ella lo hicieron las vanguardias artísticas) de la ausencia de un público lector. Sin embargo, esto no fue lo esencial. Durante décadas, la sociología latinoamericana, a pesar de esta limitación de facto, no cesó, incluso a través de la activa participación política y partidaria de muchos investigadores, de dirigirse 
imaginariamente a "la" sociedad. En este contexto, el uso prioritario del inglés sella este cambio, a saber, que los investigadores sociales son institucionalmente invitados a elegir como interlocutor privilegiado a sus propios colegas tanto en el extranjero como en sus propios países.

Esto es lo esencial. Entendámoslo por eso bien: las exigencias de profesionalidad en el momento actual tienen sin duda la virtud de crear un universo de producción donde la mirada de los colegas (los otros significativos) definen legítimamente estándares de calidad dentro de la disciplina. Dada la historia social de las ciencias, el proceso no solo es ineluctable, sino también indispensable. No es esto, por supuesto, lo que está en discusión. Lo que está en litigio son las modalidades de esta profesionalización y su evaluación, y, sobre todo, las consecuencias colaterales - pero decisivas en términos de imaginación sociológicaque puede traer; por razones lingüísticas, la reorientación del destinatario del trabajo de las ciencias sociales.

La hipótesis que formulo puede enunciarse simplemente: no se piensa y no se hace la sociología de la misma manera según el destinatario al cual se apunta. Cierto, por el momento, la mayor parte de los sociólogos siguen escribiendo libros y cada vez más artículos en castellano o portugués; frecuentan -incluso con mayor asiduidad que la generación precedente- los medios de comunicación; e incluso un número nada desdeñable de ellos no desestiman participar en movimientos sociales o asumir, si la oportunidad se presenta, posiciones en la administración pública o en los gobiernos. Todo ello es cierto. No obstante, una transición está en curso. El público lector amateur no es más el principal destinatario imaginario de la producción sociológica.

Utilizaré voluntariamente una fórmula excesiva para dar cuenta de uno de los riesgos mayores que se esconde detrás de esta transición: la consolidación de una sociología de enclave. ¿Qué debe entenderse por este término? La producción de una sociología que, no solamente en analogía con el arte moderno se escinde del público, sino de una sociología que termina escribiéndose -o sea pensándose- en referencia exclusiva a debates y problemáticas intelectuales alógenas. EI nacionalismo no es por supuesto ninguna virtud intelectual en las ciencias sociales, pero la sumisión de las preguntas sociológicas a interrogantes propios de un campo intelectual externo no es, tampoco, y se mire por donde se mire, el signo de una virtud científica. La voluntad por imponer cánones de evaluación estandarizados a las ciencias 
sociales en América Latina es un objeto legítimo de discusión en cuanto a saber si es o no la mejor vía para obtener la "excelencia". Pero la respuesta a esta pregunta no debe descuidar el hecho que la manera como este proceso se practique tendrá consecuencias sobre el quehacer de la sociología.

Algunas de estas consecuencias pueden ser negativas y no se limitan solamente a la pulsión a la publicación (publish or perish) 0 al incremento contra-productivo de la competencia entre investigadores. Lo que termina estando en juego es algo mucho más esencial: la capacidad de una sociedad, a través de sus investigadores sociales, de definir la pertinencia de las preguntas que desea formularse sobre ella misma. Es esto lo que garantizó ayer la sociedad nacional como destinatario imaginario y que compromete hoy la elección exclusiva de los colegas (y en última instancia aquellos de los países del Norte). ¿Por qué? Porque la selección y la publicación posible de artículos por revistas en este campo intelectual $-y$ la exclusión, dicho sea de paso, del libro- implica casi siempre escoger ciertos temas y abandonar otros, dar ciertas referencias bibliográficas y descuidar otras ${ }^{11}$. Procesos que estructuran las relaciones de poder y de influencia en las ciencias sociales.

Propongamos tres ilustraciones. En primer lugar, es preciso entender que no es la lengua "inglesa" lo que está en cuestión: los economistas marxistas británicos (que por vocación y talento lingüístico se expresan en inglés), no cesan de denunciar lo que en términos de carrera profesional, de prestigio, pero sobre todo de pluralidad intelectual supone la hegemonía de una perspectiva intelectual específica (la denominada economía standard o mainstream) a la hora de la evaluación, en inglés, de su producción vernácula - en lengua inglesa-. El objetivo de la reflexión no es tal o cual lengua, sino la autonomía de las preguntas.

En segundo lugar, traeré a colación un ejemplo francés. A fines de los años 1990, el gobierno socialista de Lionel Jospin implementó el paso a las 35 horas de trabajo semanal. La medida ha sido - y sigue siendomuy discutida, sobre todo, en lo que respecta a sus méritos en la

\footnotetext{
${ }^{11}$ Por lo esencial referencias al trabajo de los investigadores del campo nacional de la revista; un proceso de citación incluso activamente estimulado por los propios comités de lectura que invitan a los autores que someten artículos a citar a otros artículos ya publicados en la misma revista...
} 
creación de empleo. Se trata de un asunto importante en sociedades como las europeas en donde el paro es tan significativo desde hace varias décadas. y bien, el carácter fuertemente "nacional" de esta medida (aunque no exclusivo a Francia), no motivó al grueso de los economistas, al punto que, hasta hace poco, solo escasos estudios habían propuesto evaluaciones de esta medida. ¿Por qué? Porque elegir este tema (y los esfuerzos de especialización, trabajo y tiempo que supone), no parecía "vendible" en vistas a una posible publicación en una revista reputada del mainstream económico. El objetivo de la reflexión no es tal o cual lengua, sino la autonomía de las preguntas.

En tercer lugar, las ciencias sociales sobre América Latina pueden servir como espejo retrovisor para comprender lo que a término induciría una estrategia generalizada de comunicación entre pares. Regresaremos sobre este punto en el apartado siguiente, pero la existencia de un importante campo intelectual alrededor de los Latin American Studies en Estados Unidos, da una visión - grandeur nature- de lo que serían unas ciencias sociales totalmente convertidas a la elección exclusiva de los colegas como destinatarios de la producción. O sea, una verdadera sociología de enclave, en donde el investigador, no solamente redacta artículos para otros sociólogos (experiencia normal en una disciplina científica), sino que formula preguntas, discute con colegas, y moviliza referencias que, tratando de cuestiones sociales que conciernen a un determinado país latinoamericano, lo hace desde una exterioridad radical. O sea, formula sus preguntas desde las problemáticas intelectuales de su propio país, discute esencialmente con colegas de su propio campo nacional, y cita casi exclusivamente referencias bibliográficas de su entorno profesional inmediato. Obviamente, un análisis bibliográfico daría una conclusión menos caricatural y más matizada, pero escondería lo esencial: a saber que más allá de la "nacionalidad" de las citaciones el espacio intelectual desde el cual se formulan las preguntas, y cómo se las formula, se hace desde un campo intelectual que tiende a clausurarse sobre sí mismo. El resultado, hoy por hoy (pero la tendencia puede variar en el futuro), es evidente: a pesar de su importancia numérica, y de la calidad indudable de muchos trabajos publicados en las revistas propias a este campo intelectual, esta producción se dirige en mucho a investigadores que se encuentran dentro de este mismo campo. Se trata de una producción de enclave, ampliamente desconocida por los investigadores mainstream en los mismos Estados Unidos, y en mucho ampliamente desconocida por los 
investigadores que trabajan en América Latina sobre América Latina. El objetivo de la reflexión, una vez más, no es tal o cual lengua, sino la autonomía de las preguntas.

La reflexión sobre la lengua permite abordar un aspecto importante de la producción de la sociología sobre América Latina: la existencia de una división asimétrica, pero nunca unívoca, de relaciones de fuerza que tiende a renovarse en sus pesos específicos. Por un lado, el proceso de evaluación que privilegia la publicación en revistas académicas indexadas, sobre todo pertenecientes al campo intelectual del Norte (y básicamente estadounidense) impone sin duda un cierto tipo de hegemonía. Pero, por otro lado, en lo que concierne específicamente las ciencias sociales sobre América Latina, por el momento, el ámbito nacional sigue siendo el principal espacio, sino de legitimación, por lo menos de reputación y de audiencia intelectual. Más simple: la importancia de las publicaciones en el campo de los Latin American Studies no garantiza paradójicamente ninguna verdadera audiencia a los trabajos de un investigador; por el contrario, la importancia de la audiencia de un investigador en un ámbito nacional le garantiza, tarde o temprano, su presencia (en citaciones de artículos, conferencias, eventualmente traducciones) en el campo de los Latin American Studies.

En resumen, detrás de la cuestión de la lengua que se usa, y de los destinatarios imaginarios que se eligen, se juega, hoy por hoy, una parte del destino de las ciencias sociales sobre América Latina.

\section{POSICIONES Y LUGARES}

Partiendo una vez más desde mi propio perfil grupal, quisiera explorar un segundo conjunto de desafíos. Hasta el momento he empleado sin mayor precisión las expresiones de contextos de producción y la noción de campo. Uno y otro son términos habituales en las ciencias sociales, e inmediatamente comprensibles en sí mismos. Pero el momento ha venido de esclarecer lo que entiendo por contexto de producción, y por qué, sobre todo, me parece indispensable diferenciar entre posiciones y lugares.

\subsection{De los campos}

La noción de campo intelectual, desarrollada por Pierre Bourdieu (1984), ha tenido un éxito indudable. Varios estudios han sido así efectuados desde la teoría de los campos a propósito de la intelligentsia 
latinoamericana ya sea para mostrar su vigencia, ya sea para señalar sus límites (Pécaut, 1989; Sigal, 2002). Desde la perspectiva de este artículo, lo más importante, si se adopta el marco teórico de los campos, sería, en el momento de fuerte internacionalización de las ciencias sociales, lograr complementar la lectura nacional del campo intelectual con sus ramificaciones dentro de un campo más globalizado. En términos simples: a las posiciones del campo intelectual específicas al perímetro nacional que ocupa un agente habría que añadirle las posiciones -en verdad, las redes más o menos "subterráneas"- que posee en otros campos intelectuales.

Sin menoscabo de la plausibilidad de este esfuerzo, la novedad de esta situación es real, incluso si debe interpretársela desde una cierta continuidad. Las ciencias sociales latinoamericanas fueron durante mucho tiempo ejercidas por un número muy reducido de profesionales, en un número aún más reducido de centros de enseñanza o de investigación. Cierto, esto no impidió la existencia de jerarquías: en muchos países de la región, trabajar en una universidad capitalina siempre tuvo más valor que en una en provincia, y en una "buena" universidad capitalina fue mejor que en otra más periférica. Pero este campo intelectual, en verdad esta escena local de jerarquías institucionales, fue doblada (y triplicada...) por otras escenas, en función, por ejemplo, de las redes o contactos que alguien tenía o no con colegas del Norte, con partidos políticos nacionales, más tarde con ONG u organismos internacionales.

En todo caso, es indudable que la revolución educativa de las últimas décadas (el notable incremento de estudiantes universitarios en la región, que se acompañó con un aumento de universidades y de puestos de trabajo), han sentado las bases para nuevas lecturas institucionalizadas, estratégicas y conflictivas, de las diversas posiciones profesionales $^{12}$. El campo, y una lectura desde las posiciones en el campo, aparece entonces como pertinente para caracterizar (si se adhiere a esta teoría social) las incidencias que los contextos sociales tienen sobre la producción de unos y otros. Una estructura de

\footnotetext{
${ }^{12}$ Por supuesto, el campo sociológico es sin duda de naturaleza muy distinta en México o Brasil que en el Perú o Bolivia. Sin embargo, y sin negar lo que los efectos de talla implica, en todos lados es posible observar posiciones y jerarquías; aun cuando solo se pueda verdaderamente hablar de efectos de un campo cuando existen varios departamentos de sociología, coloquios de investigación frecuentes, un ranking nacional de revistas especializadas, normas extendidas de evaluación profesional.
} 
interpretación que puede aplicarse, me parece, a los investigadores que se insertan plenamente en el campo nacional, pero que sólo describe parcialmente, y con reparos, a la experiencia de muchos emigrados, fronterizos, inmigrantes o foráneos.

\subsection{De los lugares}

En estos perfiles, la experiencia de la producción, sin abolir los efectos del campo propiamente dichos, invita a una lectura menos inclusiva desde ellos. Por dos grandes razones. En primer lugar porque el itinerario personal metamorfosea el efecto del campo. Ningún romanticismo biográfico subyace a esta frase: se trata solamente de reconocer lo que la experiencia personal y vivida, por lo menos de dos sociedades, produce e induce en la subjetividad y desde ella en la imaginación sociológica. Una experiencia que paradójicamente es común tanto a aquellos que trabajan en una sociedad distinta a la que nacieron y aquellos que trabajan sobre sociedades distintas a aquellas en las que viven y nacieron. ¿Es necesario decirlo? El elogio epónimo que Simmel hace del extranjero como héroe de la modernidad se inscribe en esta estela: una frialdad reflexiva, producto de una intelectualización inevitable e introspectiva, en el comercio con los hombres.

En segundo lugar, porque en función de los diversos países en los que se trabaja, la investigación sobre América Latina no siempre se realiza en lo que puede denominarse campos intelectuales constituidos. Si esta situación describe globalmente el campo nacional de las diferentes sociologías en la región, y también describe -incluso sobre todo- el campo de las ciencias sociales sobre América Latina en los Estados Unidos, no describe verdaderamente, o sólo muy marginalmente, la experiencia de la producción profesional en Europa (y por ende el de mi propio perfil profesional).

Esta doble realidad hace que el lugar - los lugares- que se habitan desde estos perfiles de investigadores sociales se conviertan en un factor importante a la hora de comprender sus condiciones de producción intelectual. Formulo la hipótesis de la manera más simple posible: en este perfil, los lugares que se habitan no reenvian nunca exclusivamente (o verdaderamente) a una posición en un campo intelectual. Por un lado, la extranjeridad biográfica introduce en estos perfiles (como lo acabo de evocar) una distancia subjetiva particular; por el otro, el investigador produce estudios sobre América Latina en un ámbito institucional que, dada su exigüidad, no puede, a menos de 
forzar al exceso el sentido del término, ser asociado a un campo. En los dos casos, por razones distintas, el individuo percibe su perfil como un lugar singular, sin duda común a otros (lo que señala la similitud de los perfiles), pero que se vive, casi siempre, desde su diferencia.

Expliquemos mejor estos dos procesos. Por un lado, y para disipar todo malentendido, apoyémonos en los propios testimonios de Pierre Bourdieu, el creador de la teoría del campo intelectual. Como se sabe, en sus reiteradas digresiones de auto-reflexividad sociológica presentes en muchos de sus libros y artículos, Bourdieu no cesó de revindicar, a causa de sus orígenes de clase, que él caracterizó como populares y provinciales, su distancia con el campo intelectual parisino, $y$, en parte, explicó -y legitimó- desde su biografía, la especificidad de su mirada, que siempre caracterizó como crítica, sobre el mundo social. La dualidad que reivindica Bourdieu en nombre de su itinerario social, $y$, por ende, su pertenencia "atípica" al campo intelectual, vale a fortiori para todos aquellos que se definen desde una extranjeridad cultural (y por ende muchas veces social). Por el otro lado, el lugar que poseen estos investigadores, no es siempre una posición en un campo intelectual, porque muchos investigadores sobre América Latina definen sus temáticas de investigación y orientan sus carreras profesionales independientemente de una representación en términos de pugnas jerárquicas dentro de un campo intelectual.

\subsection{Ecologías profesionales: heterogéneas y personalizadas}

En este punto la división de los perfiles es transversal al corte Norte-Sur. Por un lado, la experiencia estructural de extranjeridad con el solo campo nacional existe para muchos - no todos - los latinoamericanos que trabajan y residen en un país distinto al de su nacimiento (ya sea en América Latina o en otra región), y también existe para muchos sociólogos que, nacidos en el Norte, trabajan desde el Norte sobre América Latina o que se han radicado en algún país de América Latina. Por otro lado, si muchos sociólogos que trabajan sobre América Latina en la región se insertan en el campo nacional de sus países respectivos, la mayor parte de los investigadores -ya sean estadounidenses, hispanics o latinoamericanos- que trabajan en los Estados Unidos trabajan en y desde un verdadero campo intelectual. En efecto, en Estados Unidos, y por el momento sólo en los Estados Unidos, dada la importancia de la inmigración latinoamericana, de intereses geopolíticos estratégicos, así como la emergencia de corrientes 
intelectuales específicas (Subaltern Studies, Postcolonial Studies, Latin American Studies...) se han instituido departamentos y revistas específicas que han terminado por constituir un verdadero campo intelectual. Una de las grandes características de esta producción ha sido la construcción de una visión sobre América Latina producida en el Norte, y en mucho desde perspectivas más o menos marcadas por las corrientes mainstream de la propia ciencia social estadounidense. No es en absoluto el caso en Europa, aunque mal no sea por simples razones de talla.

Una vez más lo que nos interesa subrayar son los efectos posibles sobre la imaginación sociológica de estos diferenciales de contextos de producción intelectual. En los Estados Unidos, y dada la impronta institucional de los Latin American Studies, la identidad disciplinaria de la sociología se ve forzada a abrir sus fronteras, a cohabitar con las ciencias humanas (sobre todo la historia y la literatura), a privilegiar los discursos (los "textos") sobre las prácticas, y a veces simplemente a disolver las acciones sociales en puros discursos. En todo caso, este conjunto de investigadores sociales se ven constreñidos a comprenderse desde y como miembros de los Latin American Studies, o sea, definirse como los definen los miembros mainstream del campo intelectual de su propio país. Pocas cosas ejemplifican mejor esta situación que la voluntad enunciada por Alejandro Portes de querer convertirse en un sociólogo general - lo que lo llevó, conscientemente según su propio testimonio, a tomar distancias con una participación exclusiva con este ámbito profesional $^{13}$ -

La existencia o no de un campo intelectual no es muy importante en sí misma (salvo para las estrategias profesionales de sus miembros...); lo que es importante son las posibles consecuencias que la existencia de un campo genera para la producción intelectual. Una vez más, la experiencia estadounidense se revela como muy importante. La existencia en este país de un campo de estudios latinoamericanos ha permitido una clausura sobre si misma de esta producción, con una doble consecuencia. El carácter marginal de esta producción con respecto al mainstream sociológico de la disciplina - como lo señala el testimonio de Portes - se duplica con su marginalidad con respecto a la producción que se realiza en América Latina ${ }^{14}$. La fuerza del campo

\footnotetext{
${ }^{13}$ Véase su entrevista in Suárez, 2009.

${ }^{14}$ Para regresar a la descripción del aparatado anterior: son investigadores del Norte que trabajan sobre el Sur y que comunican esencialmente y prioritariamente con otros
} 
dentro de los Estados Unidos explica, paradójicamente, la poca recepción de esta producción intelectual en América Latina, a pesar de su importancia volumétrica. La situación de este perfil grupal, en los Estados Unidos, contrasta así fuertemente con el perfil grupal de investigadores que, en apariencia, tienen una situación similar en Europa, pero que en realidad inscriben su producción en universos de trabajo radicalmente diferentes, puesto que dotados de una mucha menor densidad profesional, con consecuencias significativas en lo que concierne la orientación intelectual de sus estudios.

En resumen: una visión desde los lugares en contraposición a una lectura exclusiva en términos de posiciones en un campo, aparece como una herramienta necesaria de una sociología de la sociología sobre América Latina.

\section{El Futuro de "AmÉrica LATINA"}

En tercer y último lugar, abordaré otra posible consecuencia de la pluralidad de perfiles de investigadores evocados en el primer apartado de este artículo. Exploraré la hipótesis de que esta heterogeneidad de perfiles implica - puede implicar- una metamorfosis en la noción misma de "América Latina". Pero antes de abocarme a ello, y dada la pluralidad de experiencias y perfiles de investigación, es preciso establecer si existe o no -todavía- una unidad en la sociología sobre América Latina.

\subsection{La unidad de la sociología sobre América Latina}

Es posible caracterizar la sociología sobre Latinoamérica, entre 1950 y 1980, por medio de una sucesión de cuatro grandes temáticas, cada una de ellas ejerciendo un rol hegemónico en distintas décadas: el tema del desarrollo (1950), la dependencia (1960), la dictadura (1970) y la democracia (1980) (Martuccelli y Svampa, 1993). A la luz de la producción de las dos últimas décadas -y del doble proceso de multiplicación de perfiles y de nacionalización de la sociología-, ¿pueden proponerse nuevas temáticas transversales a las distintas experiencias nacionales?

Creo que la respuesta es positiva. En la década de los noventa, lo que se impuso como temática mayor en América Latina fue la cuestión de la identidad; o para decirlo con un término que no sólo empieza con la

investigadores del Norte que trabajan sobre el Sur $-y$ eventualmente con algunos colegas-amigos del Sur-. 
letra " $d$ " sino que ofrece una caracterización categorial más compleja: la diferencia. Si la problemática ha sido omnipresente en la producción sobre América Latina desde el siglo xix -sobre todo mediante los ensayos de la identidad-, sólo en esos años la temática se convirtió verdaderamente en el eje de la producción sociológica. Fue desde el paradigma de la identidad como se analizaron las telenovelas; fue desde la identidad de la Otra modernidad ("profunda", "barroca" o "popular"), como se criticó la modernidad occidental; fue la identidad, y las diferentes gramáticas de vida, que se hicieron presentes en las luchas sociales del período (desde pueblos nativos hasta minorías sexuales, sin olvidar el movimiento de mujeres o las nuevas identidades migrantes); y fue también -en una lista que sería fácil alargar a voluntad-desde las identidades híbridas y el acceso a la modernidad cultural como se pensó la inserción de América Latina en la globalización.

¿Y en los años 2000? ¿Qué temática común señalar? Para advertirlo, es imperioso reconocer el cambio de rumbo estructural que a nivel temático es observable en la sociología sobre América Latina. La diversidad de problemáticas se convierte en el nuevo eje de la sociología sobre la región. Comprendámoslo bien: la novedad de este proceso es tal, que es imposible ceñirse únicamente a una lectura negativa de esta diversidad. La diversidad temática refleja, por el contrario, la toma de conciencia - para muchos es una verdadera declaración de independencia- de que la sociología sobre América Latina debe y puede incursionar en áreas y temáticas irreductibles a la política. Una perspectiva que implica estudiar "nuevos" actores desde "nuevas" problemáticas -en todo caso, distintos a aquellos que fueron considerados tradicionalmente como legítimos-. Por supuesto, fábricas, ciudades, escuelas y familias no han esperado los últimos lustros para convertirse en objeto de estudio de la sociología en la región; sin embargo, la legitimidad de estas temáticas pasó durante mucho tiempo por una construcción de sus problemáticas en relación con cuestiones políticas. A lo que se asistió en la última década, es a una verdadera declaración de autonomía.

Se trata sin duda de una consecuencia a nivel teórico, de los cambios que se han producido en las sociedades latinoamericanas en las últimas décadas. Pero es posible hacer la hipótesis que esta descentración temática y el reconocimiento creciente de la legitimidad de temas sociales o cotidianos independientemente de todo vínculo con la política es también el resultado - positivo- de la heterogeneidad de 
perfiles de los investigadores sociales que trabajan sobre América Latina. La profesionalidad creciente de la sociología sobre la región a la que ya hemos hecho referencia, ejerce en este punto $-y$ en parte a diferencia de los anteriores - una influencia virtuosa: la sociología puede abordar sin tapujos y desembarazada de toda sospecha de insignificancia (por falta de legitimidad política), todos los ámbitos de la vida social. Es un aporte fresco y significativo, y una prueba, por si ello fuera necesario, de los estímulos que legítimamente se pueden esperar de una apertura intelectual a lo internacional ${ }^{15}$.

\subsection{América Latina más allá del Norte y del Sur}

Otro aporte que la heterogeneidad de los perfiles de investigadores produce (sobre todo con la afirmación de los emigrados, fronterizos e inmigrantes) es una transformación a nivel de las denominadas especificidades de América Latina. Debido a la factura misma de las relaciones establecidas entre el Norte y el Sur desde hace siglos, las ciencias sociales asumieron como un hecho la existencia de dos bloques estancos: por un lado, Europa (y luego Estados Unidos), digamos Occidente o el Norte; y por el otro, América Latina (luego el Tercer mundo), hoy día, el Sur.

Esta lectura, acentuada por la mirada sinóptica que tantos intelectuales del centro proyectaron sobre América Latina, condujo a un doble error. En verdad, a un doble espejismo. Se terminó construyendo, incluso simplemente por negligencia o desconocimiento, la idea, por un lado, de un Occidente sin diferencias $y$, por el otro, una América Latina homogénea (Martuccelli, 2010b). La invención de esta doble esencialidad no fue equidistante. Si las diferencias entre países de América Latina nunca fueron del todo eliminadas, por el contrario las divergencias entre las experiencias occidentales fueron ampliamente ignoradas y amalgamadas. Y cuando estas diferencias fueron reconocidas, lo fueron únicamente con la voluntad polémica de establecer una bipartición entre un Estados Unidos anglosajón y una Europa -y América- católica y latina. De Rodó a Veliz, pasando por Morandé, esta tradición es bien conocida en la región, como lo testimonian tantos ensayos sobre la identidad latinoamericana ${ }^{16}$.

\footnotetext{
${ }^{15}$ Para una presentación de esta tesis a partir del análisis de la producción sociológica en México, cf. Martuccelli (2014).

${ }^{16}$ Sorprendentemente, esta doble construcción imaginaria, no ha sido en verdad cuestionada por los estudios postcoloniales los que en su voluntad crítica por cuestionar
} 
Mi perfil (itinerario y lugar de producción) de sociólogo de origen latinoamericano trabajando, desde Francia, sobre problemas sociales tanto europeos como latinoamericanos, me aleja radicalmente de una visión dicotómica de este tipo, pero también me aleja de toda valorización de la hibridación o del mestizaje cultural. Lo que mi experiencia profesional induce, y que creo es algo común entre los miembros de este perfil grupal $u$ otros semejantes, es un cuestionamiento inmediato de la existencia doblemente especular de "un" Occidente y de "una" América Latina.

Se trata, me parece, de una actitud común particularmente activa entre los emigrantes, los inmigrantes y los fronterizos. En estos casos, incluso por razones disimiles, las diferencias nacionales e intrarregionales dentro de cada "bloque" son un horizonte natural e inmediato de la comprensión sociológica. En los unos, entre los fronterizos, porque la diferencia entre los países de América Latina deviene sustancial a medida que, por lo menos, dos experiencias nacionales son objeto, por ejemplo, de investigaciones exigentes. En los otros, sobre todo los emigrantes -en parte los inmigrantes-, porque la inserción profesional en el Norte o en el Sur, y sobre todo la realización de indagaciones empíricas en los nuevos países de residencia, permite romper con la imagen estereotipada de las sociedades centrales y modernas. En breve: para estos perfiles de investigadores tanto "América Latina" como el "Norte" dejan de ser nociones inocentes e ingenuas. Se trata de un proceso de liberación de dos imágenes especulares.

Por supuesto, si los itinerarios personales vividos por unos y otros llevan por lo general a un cuestionamiento inmediato y evidente de estos dos bloques, esto no debe traducirse, a su vez, por una esencialización biográfica. Lo importante no son las trayectorias per se de migración. Es obvio que esta experiencia común no garantiza en modo alguno la

la representación dominada del Sur, han terminado incluso reforzando la estereotipia de la existencia de estos dos bloques antitéticos - como es visible en el propio trabajo fundador de Said (1987)-. En su voluntad de dividir el mundo en dos bloques estancos, el Norte y el Sur, los dominantes y los subalternos, el centro y la periferia, en su proyecto de "provincializar Europa" (Chakrabarty, 2000), estos trabajos se han encerrado en una estereotipia superada - o en vías de ser superada- del "intelectual" del Sur como la de un individuo condenado (como lo señala Spivak curiosamente en la estela de la obra de Derrida...), a la citación, la reinscripción y la redefinición (Spivak, 1993: 217). Notémoslo: Bhabba (1994) no dice en el fondo otra cosa cuando evoca la parodia - la mimicry - a la cual estarían destinados los intelectuales del Sur. Una posición extrañamente homogénea, que peca por simplismo, y que es incapaz de reconocer la heterogeneidad de itinerarios y sobre todo los efectos disímiles de los contextos de producción. 
liberación de las imágenes espectrales sobre "América Latina" o sobre el "Norte": como lo muestra cabalmente la experiencia de tantos investigadores que, teniendo este perfil grupal, no hicieron este aggiornamento conceptual. Un perfil no define un determinismo de orientaciones intelectuales, sino un abanico de posibilidades. En este sentido, puesto que todas las trayectorias personales - todas- son vividas como singulares, lo importante es comprender, no solamente lo que cada cual hace de ella, sino, y de manera más estructural, lo que un conjunto compartido de situaciones -itinerarios y lugares- implica como horizonte posible y común para la imaginación sociológica.

\section{3. ¿Hacia otra "América Latina"?}

El término de "América Latina" fue inventado por intelectuales franceses en el siglo XIX para afirmar su ascendencia espiritual y analítica sobre la región, distinguiéndola así de una América anglosajona. La expresión tuvo un éxito indudable: baste pensar en Ariel de José Enrique Rodó y su dicotomía entre la Barbarie-instrumental del Calibán estadounidense y la Civilización-cultural del Ariel latino, y su muy larga posteridad. Pero el término también ha sido el escenario de pugnas importantes, según que se afirme la identidad de la región desde la herencia indígena, española, portuguesa o ibérica (Rojas Mix, 1991) ${ }^{17}$. Se trata de debates sin duda importantes, aunque mal no sea en la medida en que, al alimentar imaginarios distintos, performan nuevas manera de leer la realidad.

Lo que me interesa una vez más no es terciar en este debate, sino preguntarme por los posibles efectos que la heterogeneidad actual de los perfiles y los contextos de producción de la sociología sobre América Latina podrian tener en esta temática ${ }^{18}$. Por cuestiones de espacio organizaré mi reflexión alrededor de dos fechas-hito, a cincuenta años de intervalo (1965 y 2015), y me preguntaré lo que los cambios evocados a nivel de los perfiles de investigación implican en lo que podría denominarse la especificidad teórica de la sociología sobre América Latina.

\footnotetext{
${ }^{17}$ Más recientemente, y de manera explícita, ciertos científicos sociales brasileros, en vínculo -o no- con el proyecto de Itamaraty (su Ministerio de Relaciones Exteriores) tienden a construir el imaginario intelectual de América del Sur. La expresión es todo menos absurda intelectualmente; pero la expresión también connota, en su perspectiva explicita de exclusión de México, una voluntad geopolítica.

${ }^{18}$ Por razones de facilidad, he empleado el término de "América Latina" a lo largo de este artículo y continuaré haciéndole en este apartado - pero el apego a esta denominación también traduce, como se verá, una toma de posición en este debate-.
} 
Evitemos aquí también todo malentendido: nada más lejos de mi análisis que querer inventar o "rescatar" una supuesta sensibilidad, cultural e identitaria, propia a América Latina. Lo que me interesa es interrogar la capacidad -o no- de la sociología sobre América Latina (o sea, producida por "oriundos" o "extranjeros", dentro o fuera de América Latina) en ser un vivero intelectual a la hora de producir interpretaciones novedosas y hacer emerger problemáticas que, más o menos específicas a la región, sean susceptibles de esclarecer otros contextos regionales ${ }^{19}$.

Primera conclusión: 2015 no puede -bajo ningún punto de vistaleerse con los ojos de 1965. En la década de los sesenta y comienzos de los setenta, uno de los grandes rasgos de la sociología sobre América Latina fue la afirmación analíticamente específica de los problemas sociales de la región e incluso una mirada latinoamericana específica sobre el mundo ${ }^{20}$. La escuela de la dependencia, con todos sus matices y derivados (de la filosofía de la liberación a la teología de la liberación, pasando por la reactivación del ensayo de la identidad) marcan este período. Por supuesto, intentos por prolongar esta preocupación son visibles en algunos trabajos actuales; sin embargo, el contraste es notorio, en lo que a esta preocupación se refiere, entre esa época y el momento actual. En todo caso es difícil poder evocar, en el periodo actual, términos tan exitosos en su eco analítico como los de sociedad dual, dependencia, colonialismo interno, heterogeneidad estructural, desarticulación.

En este esfuerzo analítico, e incluso en medio de un sinnúmero de limitaciones, se hacía notoria una preocupación particular: no se trataba tanto de caracterizar la identidad de los latinoamericanos, sino crear (o recrear) categorías teóricas con el fin de explicitar las especificidades de las sociedades de la región. Curiosamente, y a pesar de la heterogeneidad creciente de los perfiles de los investigadores sociales, y de su inserción plural en diferentes contextos profesionales y nacionales, esta preocupación es hoy, curiosamente, menos presente y activa. Por supuesto, las especificidades locales y nacionales son subrayadas en los trabajos empíricos, pero el reconocimiento de las

\footnotetext{
${ }^{19}$ Para un ejemplo de esta preocupación desde los estudios africanos, Comaroff y Comaroff (2012).

${ }^{20}$ Ejemplo de esto último es el centro de estudios que en estos años, y desde su exilio, fundó en México, el chileno Luis Maira (1984) para estudiar los Estados Unidos. De la misma manera que el "centro" producía una mirada interesada hacia la "periferia" era indispensable poseer - argüía - un conocimiento desde la periferia del centro.
} 
particularidades contextuales no lleva, sino marginalmente, y en menor proporción en 2015 que en 1965, a teorizar estas especificidades. Curiosamente, la heterogeneidad creciente de perfiles coincide con una comprensión analítica similar de los problemas sociales. Por supuesto, no alego ni contra la necesaria unidad disciplinaria de la sociología, ni a favor de la oscuridad de todos aquellos que proponen "genuinas" lecturas macondistas sobre una América Latina "profunda". La cuestión que traigo a colación es distinta, y concierne a la inhibición de la cual hacen gala tantos investigadores sobre América Latina a la hora de prolongar sus trabajos de campo con una elaboración teórica original. Original, o sea a través de categorías que, sin que se conciban como siendo únicamente idóneas o exclusivas a la realidad latinoamericana, son construidas desde ella para dar cuenta, como herramientas específicas de análisis, de ciertos fenómenos sociales. La ausencia de este esfuerzo teórico es tanto más sorprendente que en las últimas décadas un conjunto de fenómenos sociales tradicionales de las ciencias sociales sobre América Latina se han convertido en temas mayores de la sociología internacional - por citar solo algunos ejemplos entre otros, globalización [dependencia], populismo, informalidad, transiciones, hibridación [mestizaje], detenidos-desaparecidos.

Esta inhibición intelectual, metamorfosea el sentido intelectual que el horizonte de "América Latina" introdujo como exigencia en las ciencias sociales de la región. En su defecto, la región se transforma, a ojos de muchos, en una región más de la globalización y de la modernidad. Es probable que esta postura intelectual sea el resultado de un juicio crítico hacia el esencialismo identitario de períodos precedentes, pero también es posible pensar que se trata de otro de los resultados de las nuevas exigencias de evaluación académicas. Los trabajos de los sociólogos sobre América Latina, en su búsqueda por conversar -y ser publicados - en revistas indexadas internacionales, se verían "forzados" a movilizar el lenguaje hegemónico imperante en ellas. Digámoslo claramente: la interpretación de esta tendencia por causa de un imperialismo académico es muy discutible. Nada impide - al contrarioque la formación de categorías novedosas, fruto de teorizaciones sociales exigentes, a partir de contextos sociales específicos, encuentren un eco en revistas internacionales.

Para dar cuenta de este abandono tendencial de la inquietud por producir teoría social a partir del horizonte intelectual de la "América Latina", en beneficio de la mera aplicación a la región de métodos e 
interpretaciones sociológicas producidas en otros lares, creo que es necesaria otra hipótesis. A pesar de la interpenetración creciente de las economías en la región, e incluso de la circulación de investigadores, en las últimas décadas la sociología sobre América Latina, sobre todo aquella producida en los países de América Latina, ha conocido un proceso activo de nacionalización.

A pesar de los discursos sobre la globalización ${ }^{21}$, hoy por hoy, las experiencias de los actores sociales, como en el fondo el espacio de la discusión intelectual de la sociología sobre América Latina, es profundamente nacional. Nada lo atesta mejor que el desinterés manifiesto que los sociólogos que ejercen en un país latinoamericano tienen por las sociologías nacionales producidas en otros países de la región (un aspecto muy visible a nivel de las bibliografías). Cierto, referencias cruzadas existen en más de un trabajo, pero en el fondo, no existe nada de equivalente a lo que el paradigma de la dependencia - $y$ las experiencias de exilio de los años sesenta y setenta- produjeron en término de integración de problemáticas en la sociología sobre América Latina. Arriesgo la analogía: del mismo modo que tras la narrativa del boom de los años sesenta (en mucho - no lo descuidemos-, invención editorial de Seix Barral en Barcelona) la literatura latinoamericana se renacionalizó, a partir de los años ochenta, tras el periodo de los pioneros y de los clásicos, la sociología sobre América Latina se ha nacionalizado de manera progresiva. Es, por supuesto, también, una de las consecuencias de la consolidación de campos intelectuales nacionales.

\footnotetext{
${ }^{21}$ Una digresión se impone en este punto. La inserción del tema de la globalización en la larga descendencia de la escuela de la dependencia (algo que se refleja incluso en la trayectoria de Manuel Castells) no ha recibido toda la atención que merece. Pero lo que más impacta de esta producción, salvo honrosas aventuras más o menos pioneras en Brasil o México, es la inhibición intelectual de la cual hace gala la sociología sobre América Latina en la era de la globalización sobre todo en dirección de otras regiones del Sur. El Sur -el Otro Sur: África y Asia - sigue sin existir a los ojos de los sociólogos latinoamericanos. La mayor parte de los trabajos de la globalización, marcados por el paradigma de la sociedad informacional, se inscribe en la senda bien trazada de las relaciones asimétricas de América Latina con los Estados Unidos y Europa. Y, sin embargo, esto también es parte o debería serlo, del horizonte intelectual del momento actual de la producción de la sociología sobre América Latina. Reconozco que aunque sea de manera muy tímida, progresivamente, surgen ciertos trabajos escritos por latinoamericanos sobre el Japón o África; que convenios de colaboración científica - alimentados por el fuerte incremento de los intercambios económicos con Asia- se firman; que estudios sectoriales sobre la economía de otras regiones del Sur, o desde la sociología del trabajo y de la inmigración, se producen. Sin embargo, aquí también, lo esencial se jugará a nivel de la imaginación teórica y en el aggiornamento de las interpretaciones.
} 
Cierto, los libros que recopilan alrededor de una temática común estudios provenientes de diversas experiencias nacionales son muy frecuentes. Pero la compilación de experiencias rara vez desemboca en una verdadera sociología comparada sobre América Latina. Las recopilaciones editoriales esconden mal el desinterés -en algunos, incluso una verdadera ignorancia- hacia la diversidad de otras experiencias nacionales en América Latina. El fenómeno es sorprendente porque los sociólogos - qué duda cabe-viajan cada vez más; se cruzan con mayor frecuencia en congresos internacionales; se invitan recíprocamente; algunos dictan clases con cierta regularidad en otros paises, tienden a abrirse maestrias sobre estudios latinoamericanos - sobre todo en Brasil-, e incluso se incentivan las tesis doctorales trabajando sobre distintas experiencias nacionales. Sin embargo, por el momento, todo esto parece no invitar -o sólo al margen - a la producción de verdaderos estudios teóricos comparados sobre América Latina.

¿Por qué? Porque creo que se ha debilitado, en aras del espacio nacional, la exigencia intelectual -e imaginaria- que introducía en el trabajo de la sociología de la región el horizonte teórico de "América Latina". Cierto, en muchos casos, la evocación del término ("América Latina"), careció de toda verdadera sustancia analítica; pero en otros casos, fue un horizonte compartido y exigente de imaginación sociológica.

Formulo otra hipótesis, esta vez, como un posible diagnostico tendencial: en los lustros que vienen, es probable que el futuro de la exigencia de "América Latina" como horizonte de reflexión dentro de la sociología (o sea dejando de lado los discursos identitarios de los estudios subalternos y postcoloniales), sea activamente asumida y animada, por razones diversas, por los emigrantes, los fronterizos y algunos foráneos. La hipótesis no encierra ninguna herejía: al final de cuentas la noción misma de "América Latina" fue desde su inicio una invención alógena y en su decurso analítico el término nunca cesó de ser animado y recreado por investigadores que poseían formas de inserción profesional inconsistentes, como en el caso de tantos exiliados. Mañana es posible que el futuro teórico del horizonte de "América Latina" sea la obra de investigadores cuyo campo nacional es muy exiguo o cuya situación en los campos nacionales hace que sólo trabajando en un área de estudio global - "América Latina"- les sea posible dotarse de una identidad temática y profesional. 
En este sentido, y luego de las críticas que en términos de riesgo de clausura intelectual he deslizado hacia ciertas derivas de los Latin American Studies, en este punto, es imposible no rendirles un homenaje. Si sus efectos pueden ser deletéreos a nivel de la significatividad de las preguntas sociológicas, sus efectos pueden, por el contrario, ser virtuosos a la hora de mantener en vida, no el imaginario, sino el horizonte de exigencia intelectual de "América Latina". En contra de las tendencias estructurales alimentadas por la consolidación creciente de los campos nacionales, y por ende a la reclusión de la sociología en estrictas fronteras y debates nacionales, este perfil grupal invita, incluso por razones de estrategia profesional, a entretener la legitimidad intelectual del horizonte de "América Latina".

\section{CONCLUSIONES}

El objetivo principal de estas reflexiones, realizadas desde una experiencia y una trayectoria profesional específicas, es contribuir a una auto-reflexión colectiva sobre lo que es posible caracterizar como un momento particular de las condiciones sociales de producción de la sociología sobre América Latina. Un momento en el cual, en gran parte a causa de la aparición de nuevos perfiles profesionales asociados a fenómenos de formación, migración o trabajo, a la generalización de la evaluación o a la jerarquización de las carreras y de los centros de investigación, la producción sociológica toma nuevos derroteros.

En este contexto, de manera no exhaustiva, tres cuestiones me han parecido particularmente relevantes. En primer lugar, la consolidación de una comunicación y de contactos profesionales de un nuevo tipo con la producción científica europea y sobre todo estadounidense, y tras ello, el afianzamiento creciente de un nuevo destinatario de la producción sociológica, más dirigida a los colegas que al público. En segundo lugar, la multiplicación de experiencias de producción desde "lugares" diversos, alejados unos de otros, más marcados por itinerarios personalizados que por una inserción clara dentro de un campo nacional de investigación. Por último, un desinterés latente pero creciente por la cuestión de "lo" latinoamericano y del horizonte de cuestionamiento teórico que esto implicó en el pasado, y al mismo tiempo, la clara asunción de la legitimidad de nuevos temas sociales, independientemente de su relación con los debates de sociedad o los asuntos de la agenda política. 


\section{Bibliografía}

Amselle, J.-L., 2008, L'Occident décroché, Paris, Stock.

Araujo, K., D. Martuccelli, 2012, Desafíos comunes, Santiago, LOM Ediciones, 2 tomos.

Bhabba, H., 1994, The Location of Culture, London, Routledge.

Bouilloud, J.-Ph., 2007, Devenir sociologue, Paris, Erès.

Bourdieu, P., 1984, Homo Academicus, Paris, Minuit.

Chakrabarty, D., 2000, Provincializing Europe, Princeton, Princeton University Press.

Comaroff, J., J. L. Comaroff, 2012, Theory from the South, Boulder, Colorado, Paradigm Publishers.

Maira, L., 1984, Los Estados Unidos. Una visión latinoamericana, México, F.C.E.

Martuccelli, D., 2007, "La névrose du large et les mondes parallèles", in Les cahiers du laboratoire de changement social, $\mathrm{n}^{\circ} 11$, pp.117-143.

Martuccelli, D., 2010a, "Critique de la philosophie de l'évaluation", Cahiers internationaux de sociologie, numéro double, vol.CXXVIII-CXXIX, pp.27-52.

Martuccelli, D., 2010b, ¿Existen individuos en el Sur?, Santiago, LOM Ediciones.

Martuccelli D., 2014, "Postfacio. La sociología en México, ¿un nuevo momento histórico?", in H. J. Suárez, K. Pirker (éds.), Sociólogos y su sociología. Experiencias en el ejercicio del oficio en México, México, Instituto de Investigaciones Sociales-UNAM, pp.375-388.

Martuccelli, D., M. Svampa, 1993, "Notas para una historia de la sociología latinoamericana", Sociológica, año $8, n^{\circ} 23$, setiembre-diciembre, pp.75-95.

Martuccelli, D., M. Svampa, 1997, La plaza vacía, Buenos Aires, Losada.

Ortiz, R., 2009, La supremacía del inglés en las ciencias sociales, Buenos Aires, Siglo XXI.

Pécaut, D., 1989, Entre le Peuple et la Nation, Paris, Ed. de la Maisons des Sciences de l'Homme.

Rojas Mix, M., 1991, Los cien nombres de América, Barcelona, Ed. Lumen y Ed. Andrés Bello.

Said, E.W., 1987, L'orientalisme [1978], Paris, Seuil. 
Sigal, S., 2002, Intelectuales y poder en la Argentina: la década de los sesenta, Buenos Aires, Siglo XXI.

Sorj, B., D. Martuccelli, 2008, El desafío latinoamericano, Buenos Aires, Siglo $\mathrm{XXI}$.

Spivak, G., 1993, Outside in the Teaching Machine, New York and London, Routledge.

Suárez, H. J. (ed.), 2009, Tertulia sociológica, México, Bonilla Artigas Editores.

Suárez, H. J., K. Pirker (eds.), 2014, Sociólogos y su sociología. Experiencias en el ejercicio del oficio en México, México, Instituto de Investigaciones Sociales-UNAM. 